\title{
A survey on the sustainability patterns in Iranian desert architecture
}

\author{
A. Hashemi \& F. Barmaki \\ Sama Technical and Vocational Training College, \\ Islamic Azad University, Urmia Branch, Urmia, Iran
}

\begin{abstract}
Reserving natural resources, avoidance of environmental pollution, optimizing fossil fuel consumption, and coexistence with nature are all the principles of Iranian desert architecture (IDA). IDA enjoys a variety of unique features which not only comprehend aesthetic necessities but also correspond with natural and ecological capacities of its beds. Investigating the architectural composition of Iranian desert zones, it is conceived that the climate has a significant role in logical formation of the city texture as well as the architecture of these zones. Living in such a harsh climate for ages, the inhabitants have learned to find solutions to remarkably reduce the nettlesome facets of hot and arid climate. Surveying traditional desert architecture reveals some methods and techniques to solve problems of arid hot zones climate and can lead to developing sustainability patterns which can be used in modern architecture. The current paper endeavors to elaborate on some of these patterns.

Keywords: architecture, desert, architecture, energy, saving, ecological, design, sustainability.
\end{abstract}

\section{Introduction}

Currently the theory of sustainable architecture is one of the controversial issues in the field. Undoubtedly, each building ought to be in concord with its natural surrounding but the challenge is the kind of this relationship.

In the extension of Kavir (Iran's desert), humans make use of a special kind of architecture, and try to create spaces that are in congruence with climate and 
accommodate humans' spaces that are adjusted to their needs. They also introduce the climate as an essential element and item in design and make the most of the advantages and contrasts with its negative features.

Usage indexes by architects in Kavir were well-based principles which they make use of in terms of the climatic qualification of that zone.

To create a sustainable and pleasant circumstance for human life, IDA finds codes and points that not only imposes no tolls to circumference but also performs as a perfectible factor.

This paper endeavors to discuss how IDAs oppose and conform to the climatic qualifications. In fact, in considering climatic qualification we intend to survey upon the compatibility of IDA with climatic qualifications to access an efficient and pleasant condition according to the criteria and principles of sustainable architecture. Hence, we seek the answers to the following questions:

What methods are used to adjust or contrast Kavir climatic conditions to access sustainable architectures goals?

In this survey, the significance of sustainable architecture is presented, which is followed by the elaboration on the climatic qualifications and geographic conditions of desert area as the main bed of this study. Then the fundamental patterns in IDA are explored. Finally, the findings are basic bed describe the sustainable patterns in Kavir.

The present study is a descriptive research. It is a library research and investigates written documents. To achieve the aim of study, regarding resources available and their analysis, the researcher has attempted to analyze and investigate the problem from all perspectives.

\section{Sustainability definition}

Sustainability in vocabulary means persistence and continuity and is mixed with concepts such as support and protection. In this study sustainability emphasizes stability and constancy and it refers to anything which can be persistent in the future [1].

\subsection{Sustainability as a human outlook to the environment}

The constant changes in human attitude towards the world lead to a specific outlook which is called sustainability. Following the presentation of serious environmental problems such as pollution, increasing temperature of the earth, and destruction of natural sources, constant development reported by Bruntland (1987) as "common future" was applied by the Universal Environment and Development Committee [2]. Accordingly, one of the important mechanisms introduced for following constant development is urban planning and designing. In this regard sustainability architecture has been applied by architectures and urban designers. 


\section{Environmental, geographical and climatic characteristics of the Iranian desert}

The central desert of Iran is surrounded by Alborz Mountains in the North and Zagros Mountains in the East. These mountains prevent the current rainy winds from entering the catchment. Low vegetation, salty earth and low population density are some characteristics of the central desert. Low humidity and lack of cloud cause temperature changes in these areas. High temperature in hot seasons, significant differences between days and nights and intense solar radiation are among the climatic features of these regions.

\subsection{Kavir zones' architectural and urbanism traits}

We can scrutinise sustainable patterns of IDA in two levels: macro measure and micro measure.

Macro measure involves the city texture and access network and micro measure involves the equipment and techniques of building elements [3].

\subsubsection{Macro measure}

3.1.1.1 Compact settlements Traditional cities in desert areas in Iran are mainly made of a compact settlement. According to previous studies, there is a direct relationship between the concept of sustained city and accumulation. Reducing surfaces exposed to sunlight and compressing may lead to continental comfort and saving energy [4].

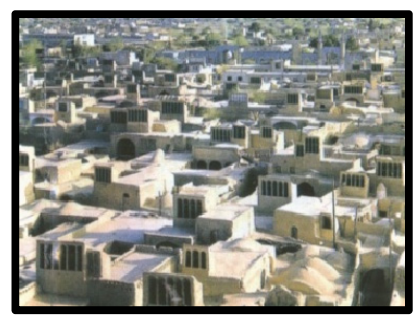

Figure 1: City compact settlements in YAZD city.

3.1.1.2 Urban planning Road networks are generated with organic order and hierarchies correspond to slope and in the direction of subterranean water, whereas erratic land division and building are constructed with a geometric order. Indirect and meander passages and porch alleys (SABAT) obstruct entering intruder winds and at the same time, its profound depth provides the most available shadow. The way of establishment of SABAT which is the manifest feature of urbanism of desert areas, provides shadow space in a suitable sequence on a pedestrian's way. In many SABATs, entrances of some houses are 
assembled which can be considered as an important factor from a neighbourhood viewpoint. Surrounding, hierarchy and observance of limits are substantiated by this urbanism which leads in social sustainability of desert areas.
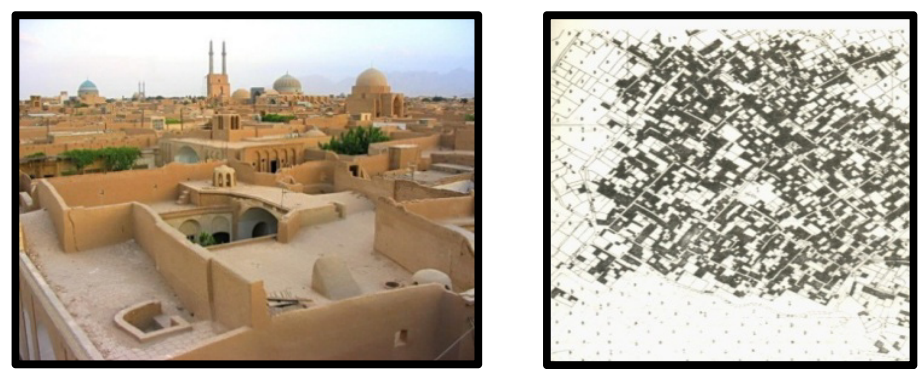

Figure 2: $\quad$ Urban planning of YAZD city.

The way of establishment of SABAT that are manifest features of urbanism of Iranian desert put a pedestrian in his way in a suitable sequence in shadow space. In many SABATs, some houses' entrances are assembled that is so important from a neighbourhood viewpoint [5].

Surrounding, hierarchy and limit observation and are substantiated by this urbanism that has resulted in social sustainability of IDA and urbanism.

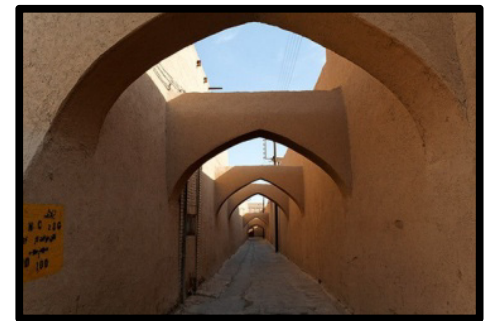

Figure 3: $\quad$ The view of alley in YAZD city with SABAT.

3.1.1.3 Green belt Compact texture of cities is surrounded by a green belt which consists of fruit orchards and farms. Thus the reflection of the sun's heat is minimized. Green spaces around the city play a significant role in preserving the central texture of the city against desert winds, dust and air dryness of these areas and are considered as one of the main factors of natural ventilation of the city. Road networks, land division and organization of full and empty spaces follow two different methods.

\subsubsection{Micro measure}

3.1.2.1 Orientation Applying natural sources and energies is one of the structural principles in traditional complexes. Old houses in desert areas face 
Qebleh. This orientation provides a climatic situation through which summer and winter spaces are placed around central yard.

3.1.2.2 Central yard Central yard is the main space of desert houses. The pool in the center of the yard takes the solar energy and provides fresh and cool air for every complex. Yards which are surrounded by covered space act like a hole and deposit the cool air at night and use it during hot days.

Gardens of trees which do not need much water provide shadow and add to the beauty of these areas and at the same time compensate the lack of humidity and make these areas suitable to live.

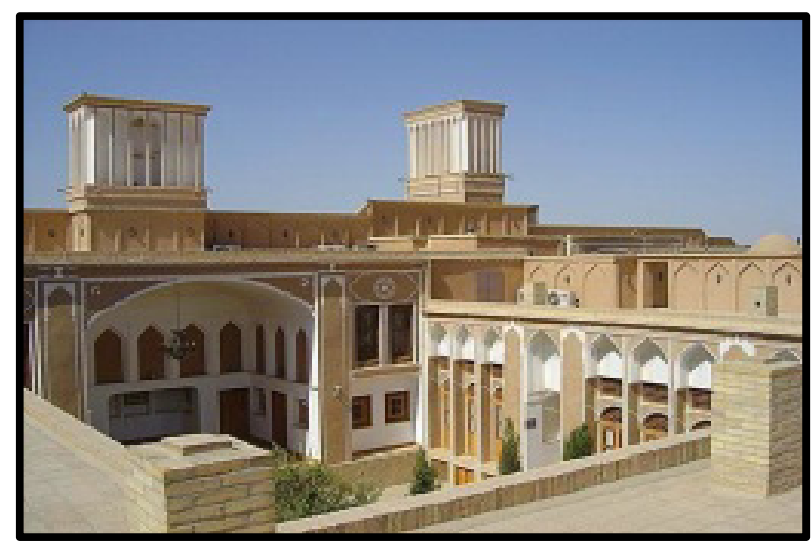

Figure 4: The view of traditional house's central yard of YAZD city.

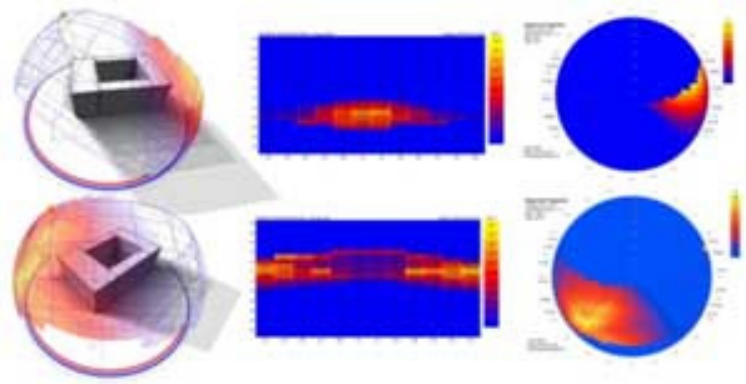

Figure 5: $\quad$ Sunshine of northern and southern faces analysis.

One of the distinguished characteristics of Kavir houses is the compatibility with climate which comprises of central yard and two northern and southern zones. Analyzing these two parts of building reveals that the sun rays to the southern zone decreases and the exposure of the northern part of building increases. 
Therefore, residents move to the northern zone at winter to benefit the maximum sunshine and move to southern zone at summer to avoid the pressure of sunshine. In this paper we attempt to analyze this architecture with AUTO DESK COTECT ANALYSE software [6].

3.1.2.3 Aqueduct Although climatic conditions of desert areas in Iran are not suitable to establish a city, invention of the aqueduct by Iranians makes it possible for them to bring water from the depths of 20 or 30 meters to the surface of the ground and as a result to continue their lives in desert areas. Using one of the most economical, healthiest and the most stable ways, residents of these areas bring water to the surface of earth and provide life conditions in desert areas important from a neighbourhood viewpoint.

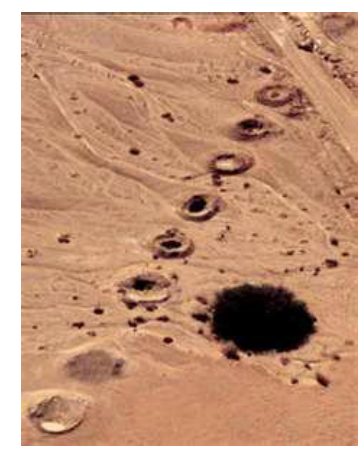

Figure 6: The aqueduct of the Iranian desert.

Independence, environment protection and no need for fossil fuel can be considered as some advantages of aqueduct for constant development. Using aqueduct is a way of groundwater extraction which conduction is a hierarchical to landscape fabrics.

Most houses, schools, mosques and bazaars are connected to the aqueduct through puddles and gutter of gardens and the size of complexes directly depend on the amount of the water of aqueduct. Independence to fossil fuel can be considered as aqueduct advantages in the direction of constant development. Using the aqueduct generates a subterranean water net that is hidden. Most houses, schools, bazaars and mosques are connected to the aqueduct by puddle and gutter of gardens and the size of living complexes directly depend on the water amount of aqueduct.

\subsubsection{SHAVADAN}

SHAVADAN is an underground space dug under the buildings in the old regions of cities of Dezful and Shushtar. Its depth is from 5 to 12 meters which can be reached by many different stair cases. According to the geotechnical specifications of the soil in Dezful area, SHAVADAN is an underground space in the depth of ground and lacks structural materials. In some cases, the walls of 
SHAVADAN are covered with gypsum and most of them are not decorated. Most of these SHAVADANs are interconnected through underground corridors.

Therefore a neighborhood-like connection will be formed underground. These twisting labyrinth structures connect many old buildings of the city together through underground tunnels. In the end, through SHAVADAN's neighboring buildings it is connected to Dezz river bed [7].

The best time to use SHAVADAN was the hot summer days, in other words besides living in the city, there was another living style in the heart of SHAVADAN's underground life. In hot days of Dezful, in summer when the heat is absolutely unbearable and the temperature rises up to 50 degrees centigrade, the temperature in the underground of SHAVADAN is stable between 22 to 25 degrees centigrade. This suitable temperature in underground space of SHAVADAN was a desirable shelter for the daily life of the citizens [7].

Otherwise, people in cities and villages who had no SHAVADAN facilities had to work and live under the shades of trees and tent in the summer.

Creating shade, air current and the use of wind tower or tents, shading trees can be clearly seen in the sustainable architecture of hot and humid regions of Iran. The effect of above-mentioned elements created narrow shady alleys parallel to current of air.

Although in sustainable architecture of these two cities (Dezful and Shushtar) narrow shady alleys can be seen, SHAVADAN underground spaces with low subterranean water are the blessings which are given by God to these two cities and this will lead the creative architects of Dezful and Shushtar to build this.

Attractive architecture with identity; therefore this intensive architectural network with narrow shady alleys and covered corridors made living possible in certain hours in the city, but life in hot hours of the. Typical of SHAVADANsection. Diagram of Dezful's town-section day is only possible in SHAVADAN. In certain seasons, the roof of the house is an ideal place for sleeping at nights. Life in Dezful has several aspects. The life goes on continuously from SHAVADAN underground space to open space of roof tops. Sleeping on the roof and living in SHAVADAN are sometimes going on habitually and have not forgotten until now [7].

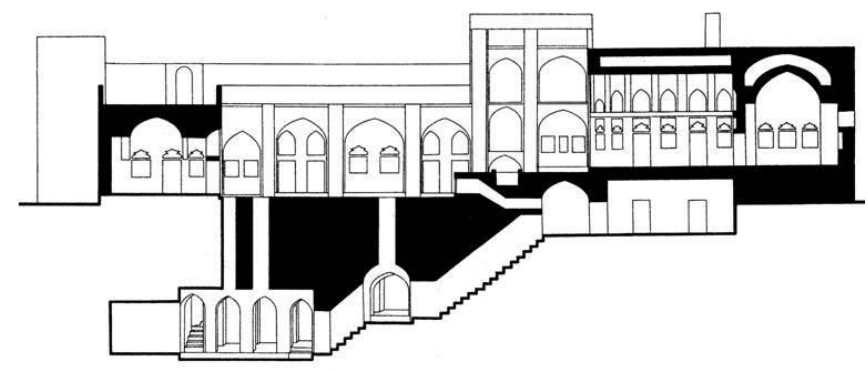

Figure 7: Section of SHAVADAN. 
In some parts of SHAVADAN there were some tall earthen jars. Inside of them there was water and they were in the direction of air current. The air current after striking the sides of HABANEHs became cold and it made the whole SHAVADAN more pleasant. The water itself in HABANEH became cool and drinkable. Also these cool spaces were desirable place for keeping perishable food safe when there was no refrigeration system. We can understand from this that, contrary to cities of Iran on the desert side which had in most places [7].

3.1.2.5 Wind tower Making wind tower (wind breakers) is one of the most important masterpieces of Iranian skilful engineers and architects.

While wind tower are beautiful and decorative, they have an important role in the ventilation of inner environment of buildings, water tanks and cold waters and they do this task in a natural way and without using any energy. Because blowing different kinds of seasonal and daily winds is one of the main features of climate in salt desert regions of Iran, the wind tower of this region were made in the direction of these pleasant and speedy winds. The top of these wind tower was kept open in one, two, four, six or eight directions, so that the top of them toward sky is closed and its bottom until the inside of the building or water tank was open [8].

Inside the column of the wind tower (except one direction wind tower) was divided into four, six or eight parts in oblique forms by partition walls and bricks, so that the direction of wind can be concordant with the entering cancel of the column of the wind tower and cause flowing the air in the inner environment of buildings, water tanks and cold waters.

At night with no wind blowing, wind tower act as a chimney and bring the cooler air of the outside area into the building via doors and windows. This air becomes hot by receiving the heat from the walls of the building and the wind tower and goes out via the top entrance of the wind tower. The entrance of the cool air into the building and the wind tower makes them cooler [8].

During the day, with no wind blowing, the wind tower acts at the opposite direction of chimney, in this way: the hot air of outside transmits its heat by contacting the walls of the wind tower that had been cooled down during the last night and after being cooled, it is drawn into the building and at last it exits from the doors and windows of the building. Blowing the wind between the entrances of the wind tower and the doors and the windows of the building makes a pressure difference that causes air flowing in the building. Because of the wind tower, this pressure difference is in a way that air enters from the top entrance of the wind tower and exits from the doors and windows of the building.

However, we can choose the location of the building in a way that air is drawn into the building by the doors and the windows of the building and it exits through the wind tower. In this way, the wind tower acts as an air fresher. It is clear that by considering different climatic situations in salt desert areas, structure and appearance of wind tower are different from each other.

In some regions that the desired wind blows just from one direction, one direction wind tower are used and in some other regions that the wind has no special direction, wind tower with three to four entrances are used. Another kind 
of wind tower is connected to the living atmosphere of the building by an underground canal. The position of this canal is under the yard and the little gardens that by watering flowers and plants, the water penetrates into it and the always wet air of the wind tower is cooled down by passing through this underground wet canal and then enters the living atmosphere before entering the rooms, this air is passing over the water pond and the formation and is cooled down [8].

By entering this cool air into the room, a very cool atmosphere is created. This is probably lower than the relaxing temperature so that the residents of the home feel cold. In fact our ancestors could create such a cool atmosphere in summer and through salt desert by this masterpiece. The most important feature of the wind tower is natural ventilation and cooling the air without using any electrical energy. In this process, the wind enters the wind tower via its top entrance by high pressure coefficient and exits from the doors and the windows of the wind tower by low pressure coefficient.

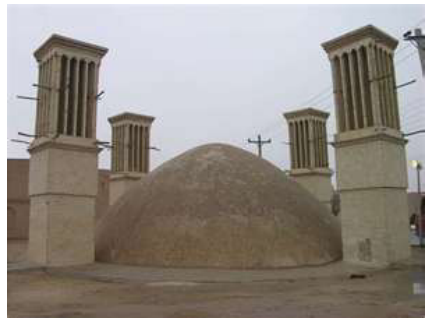

Figure 8: $\quad$ Section of a wind tower.

3.1.2.5.1 Important points in performing wind tower Choosing the location of the wind tower, the height of the column, its harmony with the atmosphere that should be cooled down and also the direction of their entrances and the number of them needed exact work and enough experience are the significant points of the wind tower building. Any fault in architects calculations had meant the entering of hot air and dust into the house, instead of cool air. The building materials of wind tower are usually raw brick, muddy brick, plaster and wood.

3.1.2.6 The structure of porch A porch creates shade. In hot summers where the sun shines almost directly, it does not enter the living place so the house does not get hot and in cold seasons of the year, because of the obliquity of the sun's light, the entering of sunshine is possible and so the house gets hot.

3.1.2.7 Construction materials Using materials that have less compression causes the cooling of the building. The materials of this region have high heat capacity and are mostly mud, raw brick or brick. Considering the climatic situation, during the day with direct and strict shining of the sun, these materials 
get the heat late and during the night they lose their heat slowly so that the temperature variance during the day and the night is balanced.

Thick mud brick walls and arched mud brick roofs which are the only variable construction material in desert areas, while accumulating and conducting the heat acts like a condenser to keep the heat or coolness of a room. The height of rooms which is caused by the arch shaped of the roof, gets a great volume of the air and avoids rooms from being hot or cold [9].

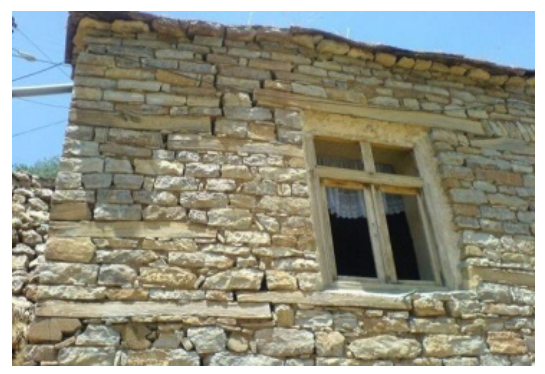

Figure 9: Construction materials.

3.1.2.8 The windows Not using big windows in south and west directions and utilizing them only in north and east directions are the characteristics of the windows.

3.1.2.9 Spaces under the soil Finally, if none of the above mentioned solutions can lessen the hot weather of desert areas, humid and cool rooms under the soil which modify temperature by gradual absorption of heat and cold can be used as the last solution [10].

3.1.2.10 Dome shaped building Building dome shaped ceiling makes it to be half sunny and half shaded when we have sunshine, besides increasing the height of ceiling and directing warm air to the highest point, which cools the chamber.

\section{Natural minimum destruction}

In addition to designing and creation of buildings with ecological view, material is produced with minimum damage, minimum usage of fossil fuel and without making construction garbage.

Muddy brick is the main construction material which is generally obtained from excavation and digging and is also mixed with other materials. In other words all the materials are local [11].

\section{Resumption}

In IDA, discarding is unmeaningful. Everything is used. Resumption and reexploitation of buildings are other features of Iranian's architecture and 
especially IDA. Grits obtained from the destruction of muddy buildings are introduced to the production cycle as the most desirable soils.

This manner rose from natural processes understanding since there is no garbage in nature, lateral production of each organism is changed to another's food. In other words, natural systems are considered to be closed loops and this is the main principle in sustainability design.

\section{Results}

Data analysis in relation to research question will be summarized. It will also address the specific areas of discussion which have been arisen from findings.

1. Kavir zones have special environmental features and architecture and urbanism in these zones that is based on special principles that are proportional to environmental conditions.

2. Kavir buildings are counted as dynamic buildings because provide their needs with the site energy and not only are compatible with their site and climate and work without producing pollution but also produce garble that are not usable in the environment directly.

3. Designing and constructing buildings should be done by ecologic vision from the energy saving natural materials using viewpoint such as soil, stone, wood and mud bricks; attention to necessary energy for maintaining and regulating environmental conditions with suitable designing of full and vacant spaces, correct orientation of buildings, using of natural energies, minimizing fossil fuel using that are considered sustainability pattern in IDA and urbanism.

4. Building in Iranian desert is distinct by give affairs to identity cultural, social and religious features and help to establishment of social and environmental and economical sustainability.

\section{References}

[1] Asadpoor, A., Sustainability in Kavir, 1st Nat. Conf. Kavir Architecture, Iran, 2006.

[2] Mousavi, M., Ecology in Norman Foster's Architecture, Memar: Iran, pp. 64-69, 2004.

[3] Hagpanah, M., Dehgani, M., $1^{\text {st }}$ Nat. Conf. Sustainable Architecture ding, Hamadan, 2009.

[4] Nagizade, M, Islam global view, Sustainable development of Iran's arid cities: Iran, p 27, 2008.

[5] Soflaee, F., Sustainable elements in Kavir. Proc. of the National. Conf. on Fuel Consumption in Building, Iran, 2003.

[6] Soheyli, M., Moazeni, M., Iranian traditional architecture analysis. Proc. of the $2^{\text {nd }}$ Nat. Conf. on Sustainability and Architecture, Hamadan, 2012.

[7] Safaee, M. SHAVADAN, The Sustainable Architecture in the city of Dezful in, Iran, pp. 1-8.

[8] Bahadorinejhad, M., Wind Tower, Yazda: Iran, pp. 13-15, 2008.

[9] Tavassoli, M., City building in Kavir, Payam, Tehran, 2009. 
38 Eco-Architecture IV

[10] Razjoyan, M., Clime and Architecture, Beheshti, Tehran, 2009.

[11] Iranmanesh, M., Sustainable architecture techniques, $1^{\text {st }}$ Nat. Conf. Clime and Building, Iran, 2011. 